\title{
The role of integrated medical and prescription drug plans in addressing racial and ethnic disparities in medication adherence
}

\author{
Alexander Ding, MD, MS, MBA; Suzanne W Dixon, MPH, MS, RDN; Erin A Ferries, PhD, MPH; \\ and William H Shrank, MD, MSHS
}

\section{Plain language summary}

Patients not taking their prescribed prescription medications can result in unnecessary sickness and death. This cost and preventable progression of disease disproportionately affects minorities. The underlying reasons for this are complex, and solutions that have shown promise have had challenges scaling. We propose that integrated (ie, combined) medical and drug plans, due to their incentive structures, are well positioned to be one scalable solution to this health equity problem.

\section{SUMMARY}

Medication nonadherence in the United States contributes to 125,000 deaths and $10 \%$ of hospitalizations annually. The pain of preventable deaths and the personal costs of nonadherence are borne disproportionately by Black, Latino, and other minority groups because nonadherence is higher in these groups due to a variety of factors. These

\section{Implications for managed care pharmacy}

This Viewpoints article suggests that integrating medical plans with managed care pharmacy plans is one scalable solution to addressing health disparities related to medication nonadherence. factors include socioeconomic challenges, issues with prescription affordability and convenience of filling and refilling them, lack of access to pharmacies and primary care services, difficulty taking advantage of patient engagement opportunities, health literacy limitations, and lack of trust due to historical and structural discrimination outside of and within the medical system. Solutions to address the drivers of lower

\author{
Author affiliations \\ Alexander Ding, MD, MS, MBA; Suzanne W \\ Dixon, MPH, MS, RDN; Erin A Ferries, PhD, \\ $\mathrm{MPH}$; and William H Shrank, MD, MSHS, \\ Humana Inc, Louisville, KY
}

AUTHOR CORRESPONDENCE:

Alexander Ding, ading@humana.com

\author{
J Manag Care Spec Pharm. \\ 2022;28(3):379-86 \\ Copyright $\odot 2022$, Academy of Managed \\ Care Pharmacy. All rights reserved.
}

medication adherence, specifically in minority populations, are needed to improve population outcomes and reduce inequities. While various solutions have shown some traction, these solutions have tended to be challenging to scale for wider impact. We propose that integrated medical and pharmacy plans are well positioned to address racial and ethnic health disparities related to medication adherence.
In the United States, approximately 125,000 deaths and 10\% of hospitalizations annually are attributable to poor medication adherence. ${ }^{1}$ In 2012 alone, nonadherence was estimated to cost the health care system between $\$ 100$ billion and $\$ 300$ billion. ${ }^{1-3}$ Prescription drug therapies are foundational to primary health care, ${ }^{4}$ particularly the management of chronic disease. It is well understood that lower medication adherence negatively affects quality of life and life expectancy. ${ }^{5-7}$

Medication adherence rates vary among different patient populations, with well-documented racial and ethnic disparities in medication access and adherence. ${ }^{8-12}$ There is significantly lower adherence to prescribed medications among Black, Latino, Indigenous, and other minority groups compared with White patients. ${ }^{4}$ These disparities persist even after controlling for socioeconomic variables, 
health status, out-of-pocket costs, and refill convenience. ${ }^{11}$ Closing gaps in how prescriptions are accessed and used by different patient populations should be part of the solution to addressing well-documented health disparities. ${ }^{13-17}$

In this Viewpoints article, we discuss the structural, social, and economic drivers of racial and ethnic disparities in medication adherence. Given the lack of explanatory power of observed variables as drivers of nonadherence,$^{18}$ and the paucity of conclusive evidence regarding optimal policy approaches to address these disparities, we introduce the concept of integrated medical and prescription drug plans to better meet the health care needs of at-risk, marginalized, and low-resourced populations. We believe integrated plans could contribute to meaningful progress on closing the medication adherence gap that contributes to health inequities in the United States. Employing these policies may offer innovative ways to bring value to health care while simultaneously providing effective supports to enhance prescription drug adherence.

\section{Drivers of Racial and Ethnic Disparities in Medication Adherence}

Decades of research point to several drivers of racial and ethnic disparities in medication adherence in the United States, such as socioeconomic factors, challenges related to prescription affordability and convenience, lack of access to pharmacies and primary care services, difficulty with patient engagement and lack of trust due to historical and structural discrimination, and limitations in health literacy. ${ }^{19-27}$

\section{AFFORDABILITY}

Prescription drug affordability is critical to accessibility and subsequent adherence. ${ }^{28-30}$ Unaffordability and inability to pay contributes to nonadherence and poor outcomes. ${ }^{6,31}$ Minority communities have higher rates of poverty, food insecurity, and housing instability, which makes these groups among the hardest hit by rising drug prices and more likely to be affected by cost-related nonadherence..$^{19-21,32-41}$

Controlling for demographics, health status, out-ofpocket costs, convenience of refilling prescriptions, and socioeconomic status attenuates, but does not eliminate, the association between race and ethnicity and adherence. ${ }^{11}$ Therefore, addressing affordability is an important component for reducing adherence disparities associated with race, but not the only step needed to close the medication adherence gap between White populations and other racial and ethnic groups.

\section{ACCESS}

Affordability does not ensure access. Although controlling for out-of-pocket costs and socioeconomic status attenuates the effect of race on adherence, it does not ameliorate it completely. ${ }^{11}$ Significant structural and systematic barriers to access remain, such as lack of access to primary care services and retail pharmacies.

A trusted physician-patient relationship, care continuity, and integrated care-all of which may be improved by regular primary care access-are associated with better medication adherence..$^{24,42-45}$ However, Black individuals are more likely to live in communities without adequate primary care access. ${ }^{22}$ This lack of access to a regular primary care provider disproportionately and directly contributes to medication nonadherence among minority individuals. ${ }^{24}$

Lack of retail pharmacy access is a significant contributor to nonadherence, as well. Many lower-income and minority residents face "pharmacy deserts," loosely defined as geographic areas lacking access to a nearby pharmacy and where pharmacy services are scarce or difficult to obtain. ${ }^{23,46-48}$ Pharmacy deserts disproportionately exist in segregated Black communities, and this disparity has widened over time, ${ }^{23}$ with documented impacts on medication adherence. $^{49}$

\section{ENGAGEMENT AND TRUST}

Structural racism and individual-level discrimination in health care contribute significantly to health disparities by driving mistrust of the medical system among Black, Latino, and other minority individuals..$^{50-53}$ Many Black patients have been exposed to breaches of trust by the US health system in our history, including the Tuskegee study and origination of the HeLa cell line, and have expressed being treated unfairly by medical staff. ${ }^{54-56}$ More broadly, social inequity adds to the mistrust of a historically White, mainstream, medical establishment among minority populations. ${ }^{27}$ Some data demonstrate that the "distrust gap" between Black and White patients has improved in recent years. ${ }^{57}$ Yet, other research paints a less-promising picture, with significantly more medical and clinician mistrust among minorities and reports of less compassionate and more hurried careexperiences and beliefs that correlate strongly with poorer prescription adherence..$^{58-62}$ Distrust drives patterns of lower health care utilization and poorer chronic condition management among Black adults. ${ }^{27,63}$

Health literacy is an individual's ability to understand and use information and services intended to inform health-related decisions and actions. ${ }^{64}$ Limited health literacy is a significant driver of health disparities and is directly related to nonadherence. A meta-analysis found health literacy to be positively associated with adherence 
for medication treatment of acute and chronic disease. ${ }^{65}$ Both African-American race and lower health literacy have been associated with decreased levels of diabetes medication adherence. ${ }^{66}$ Data suggest that up to half of older Black Americans have limited health literacy, ${ }^{67}$ and a systematic review identified health literacy as one of the more important mediators of race-related medication adherence disparities. ${ }^{68}$ It should be noted that disparities in health literacy are the result of structural forces such as lower socioeconomic status, lack of access to quality educational resources, and racism.

Taken together, these differences in trust in the health care system $^{50-53}$ and disparities in health literacy ${ }^{69,70}$ may contribute to differing beliefs in treatment value and effectiveness. ${ }^{71}$ This, in turn, may contribute to race-based adherence disparities.

\section{Approaches to Reduce Disparities in Adherence}

Over the past several decades, programs to address the drivers of lower prescription adherence have been studied in diverse populations. Many programs have been deployed on a small scale, and some show promise for reducing racial and ethnic disparities related to adherence and may be scalable. In the following sections, we briefly review some promising approaches.

\section{ADDRESSING AFFORDABILITY}

Evidence supports the role of improved affordability as a contributor to better medication adherence. The Post-Myocardial Infarction Free Rx Event and Economic Evaluation (MI FREEE) trial demonstrated that providing full drug coverage increased medication adherence in White and non-White patient groups, although this approach reduced rates of major vascular events or revascularization only in the non-White group. ${ }^{72}$ Among White, Black, or Hispanic respondents who used at least 1 cardiovascular medication, creation of the Part $\mathrm{D}$ benefit was associated with a 16-percentage point decrease in the White-Hispanic disparity in 12-month medication adherence. ${ }^{73}$ A reduction in prescription adherence was not observed between the White and Black cohorts in this study. This suggests that eliminating copays and cost sharing alone may not be enough to support improved adherence among Black patients, although a combination of approaches may be effective. For example, integrating drug affordability programs with medication regimen simplification, education, reminders, and positive financial incentives may improve prescription adherence rates among Black patients. ${ }^{74,75}$
Closely monitoring medication adherence in specific cohorts and conducting targeted outreach to identify lowcost or no-cost prescription medications, especially when done in conjunction with other interventions, may reduce disparities in access for vulnerable populations.

\section{IMPROVING ACCESS}

Mail-order pharmacy is a medication delivery service intended to increase drug access and patient convenience, and these services have been associated with improved overall adherence rates compared with adherence rates for patients using retail pharmacies. ${ }^{76,77}$ Adherence rates for statins, anticoagulants, antihypertensive drugs, diabetes medications, and many other drug classes have been reported to be higher for patients using mail-order pharmacy. ${ }^{78-81}$ Coordinating mail-order pharmacy programs with synchronization of medication refills may provide additional benefit, particularly for patients with poorer baseline adherence. ${ }^{82,83}$ While mail-order pharmacy services have resulted in improved medication adherence, previous research has demonstrated that White patients were more likely than minority patients to use mail-order pharmacy services. ${ }^{11,84}$

Further research is warranted to explore the racial and ethnic disparities associated with mail-order pharmacy use, althoughy previous explorations have uncovered lack of knowledge around mail-order pharmacy, unstable housing situations, and inconsistent access to mail delivery as barriers to mail-order use. ${ }^{85}$ There is an urgent need to address underlying systemic disparities and conduct targeted outreach to address the specific needs of individual populations. Interventions that include mechanisms for preferred channels of communication and culturally relevant outreach should be developed and tested. ${ }^{86}$

\section{IMPROVING ENGAGEMENT, EDUCATION, AND TRUST}

Building trust with minority populations is critical to engagement and education, and this, in turn, may support better prescription adherence among minority groups and better health outcomes. ${ }^{87,88}$ Public policy should focus on investing in a more ethnically diverse and representative provider workforce because these efforts can lead to increased access in underserved areas, improved cultural competence and communication, and higher patient trust and satisfaction, which ultimately facilitates better health outcomes. ${ }^{89,90}$ Allowing for more patients to receive care from a racially concordant doctor may improve medication adherence, as well. An intervention in Oakland, California, found that pairing Black male patients with Black male physicians may reduce the Black-White cardiovascular mortality gap by $19 \% .^{91}$ 
A 2017 review identified practical approaches to addressing medication adherence with the potential to attenuate disparities, including patient engagement strategies, pharmacist-led engagement, and cognitive-based behavioral interventions. ${ }^{92}$ Similarly, a systematic review found that interventions focused on engagement and education had a greater effect on adherence in lower-income and racial-ethnic minority patient groups than White and higher-income populations. ${ }^{65}$ One particularly promising approach to engagement and activation-motivational interviewing-has been shown to close gaps in adherence. ${ }^{93,94}$ At Humana, a national health and wellness organization, a motivational interviewing intervention narrowed racial disparities in medication adherence, increasing proportion of days covered among Black patients by $3 \%$, compared with $1 \%$ for White patients (unpublished data, Humana Inc., Integrated Health Services, September 2021).

Community-based approaches for improving trust in the medical system and access to high-quality information in a culturally relevant space, coupled with medication delivery services, may offer particular value for minority groups because they leverage social institutions that have preexisting social trust as an entrée into engagement and education. For example, among Black male barbershop patrons with uncontrolled hypertension, health promotion by barbers, which may improve trust, coupled with medication management delivered in barbershops by pharmacists measurably improves blood pressure control..$^{95,96}$ The medication management component, when delivered in a culturally relevant context, may improve adherence through enhanced health literacy ${ }^{66,67,69,70}$ Scalability of such programs can be a limiting factor toward greater impact.

\section{A Unique Opportunity for Integrated Medical and Prescription Drug Plans}

Despite recognizing the high prevalence of racial and ethnic disparities in medication adherence and how these disparities amplify health inequities, ${ }^{11,18,26,59,97}$ meaningful progress in impacting this challenge has been slow. ${ }^{11}$ A coordinated effort among stakeholders across the health care continuum is needed to more rapidly develop and implement promising approaches to reduce disparities in medication adherence. By better aligning financial incentives across medical and pharmacy spending, and coordinating medical and pharmacy benefits and programs, integrated medical and prescription drug plans may be well suited to address the structural limitations that have prevented progress in reducing disparities in medication adherence.
Because the cost of nonadherence often manifests in adverse clinical outcomes and downstream medical expenditures, ${ }^{98}$ investing in strategies to improve adherence not only creates improved health outcomes for the individual, it also avoids the occurrence of additional health care expenditures by the beneficiary and the payer..$^{98}$ While siloed pharmacy plans may have data on prescription medication adherence, they have little incentive to focus on adherence precisely because the pharmacy plan is not incentivized to take these steps; the value of improved adherence would be captured by the medical plan in cost savings, but not by the pharmacy plan. Evidence from our experience suggests that members in integrated commercial and Medicare Advantage plans have lower costs, fewer emergency visits, fewer inpatient admissions, and better medication adherence rates compared with plans that are not integrated. ${ }^{99,100,101}$ Further research is needed to better understand adherence outcomes between integrated and nonintegrated plans.

Integrated medical and prescription plans are also positioned to better coordinate medical and pharmacy benefits and to integrate data and interventions across medical and pharmacy programs to more holistically address medication nonadherence. This level of integration provides a mechanism to directly focus on the adherence component of health disparities and connect patients to existing pharmacy initiatives, such as medication therapy management (MTM) programs. MTM uses medical and pharmacy data to support appropriate medication use through identification of suboptimal prescription drug adherence and drug-drug interactions. For example, many integrated medical and pharmacy plans have therapeutic interchange programs that identify opportunities for beneficiaries to reduce out-of-pocket costs by switching to lower-cost prescription drugs.

Increased incentives to coordinate care allow chronic disease management programs, patient and provider education and engagement, prescription home delivery services, and medication synchronization services to be delivered simultaneously to the patient. With newer and more sophisticated predictive analytics, integrated datasets might also allow for better prediction of nonadherence, better anticipation of the most impactful interventions, and an improved efficacy and efficiency of outreach methods and channels for behavior change.

Finally, leveraging existing community and provider partnerships to build trust and engagement is another lever that integrated plans are uniquely positioned to use to address disparities in adherence. Medical plans are already working with community organizations and health care providers as part of their core business functions. But 
the inclusion of pharmaceutical plans allows plans to use these existing partnerships as a foundation on which to build medication-specific efforts and programs.

These partnerships can improve communication, build trust, improve integrated care, increase referrals, and enhance access to community health programs that can help meet the medical, social, and economic needs of each patient. This can be especially impactful when partnerships are developed with trusted community organizations, particularly those programs that have close ties within the communities they serve. This provides an opportunity to lend those community groups' social trust and to translate that into trust in the healthcare plan and provider. Examples of this includes Humana's partnership with Black churches and faith-based organizations to address medically adjacent social needs, ${ }^{102}$ such as food insecurity, transportation needs, and social isolation, as well as our recent COVID vaccine equity efforts. The challenge in this is that trust is difficult to scale quickly.

\section{Conclusions}

Disparities in medication adherence are a clear and persistent source of structural inequality in our health care system, driving downstream inequities in the health and well-being of minority populations. Progress to reduce disparities in medication adherence has been slow. ${ }^{11}$ A combination of misaligned incentives, fragmented health care delivery, poor coordination among pharmacy and medical management programs, and a failure to fully leverage community partnerships have all constrained progress. Integrated medical and pharmacy plans are structurally well positioned to address these limitations through aligned incentives and better coordination of medical and pharmacy benefits and care management activities. Further research is needed to better clarify the impact of integrated medical and pharmacy plans and related programs in reducing racial and ethnic disparities in prescription adherence.

\section{DISCLOSURES}

This study was not supported by any funding sources other than employment of all authors by Humana Inc. Humana products and programs are referred to in this article.

\section{ACKNOWLEDGMENTS}

The authors thank Lilian Ndehi, Nwando Olayiwola, and Brian Powers for their feedback on this manuscript.

\section{REFERENCES}

1. Viswanathan M, Golin CE, Jones CD, et al. Interventions to improve adherence to self-administered medications for chronic diseases in the United States: a systematic review. Ann Intern Med. 2012;157(11):785-95.

2. Iuga AO, McGuire MJ. Adherence and health care costs. Risk Manag Healthc Policy. 2014;7:35-44.

3. Neiman AB, Ruppar T, Ho M, et al. CDC grand rounds: improving medication adherence for chronic disease management - innovations and opportunities. MMWR Morb Mortal Wkly Rep. 2017;66(45):1248-51.

4. Kogut SJ. Racial disparities in medication use: imperatives for managed care pharmacy. J Manag Care Spec Pharm. 2020;26(11):1468-74. doi:10.18553/ jmcp.2020.26.11.1468

5. Kim J, Combs, K, Downs J, Tillman F III. Medication adherence: the elephant in the room. U.S. Pharmacist. January 19, 2018. Accessed December 14, 2020. https://www.uspharmacist.com/article/ medication-adherence-the-elephant-inthe-room

6. Van Alsten SC, Harris JK. Cost-related nonadherence and mortality in patients with chronic disease: a multiyear investigation, national health interview survey, 2000-2014. Prev Chronic Dis. 2020;17:E151.
7. Desai R, Thakkar S, Fong HK, et al. Rising trends in medication noncompliance and associated worsening cardiovascular and cerebrovascular outcomes among hospitalized adults across the United States. Cureus. 2019;11(8):e5389.

8. Schore J, Brown R, Lavin B. Racial disparities in prescription drug use among dually eligible beneficiaries. Health Care Financ Rev. 2003;25(2):77-90.

9. Reed MC, Hargraves JL, Cassil A. Unequal access: African-American Medicare beneficiaries and the prescription drug gap. Issue Brief Cent Stud Health Syst Change. 2003(64):1-8.

10. Lewey J, Shrank WH, Bowry AD, Kilabuk E, Brennan TA, Choudhry NK. Gender and racial disparities in adherence to statin therapy: a meta-analysis. Am Heart J. 2013;165(5):665-78, 678.e661.

11. Xie Z, St Clair P, Goldman DP, Joyce G. Racial and ethnic disparities in medication adherence among privately insured patients in the United States. PLoS One. 2019;14(2):e0212117.

12. Bhattacharjee S, Lee JK, Vadiei N, et al. Extent and factors associated with adherence to antidepressant treatment during acute and continuation phase depression treatment among older adults with dementia and major depressive disorder. Neuropsychiatr Dis Treat. 2020;16:1433-50.

13. Carratala S, Maxwell C. Health disparities by race and ethnicity. Center for American Progress. May 7, 2020. Accessed November 10, 2020. https:// www.americanprogress.org/issues/ race/reports/2020/05/07/484742/ health-disparities-race-ethnicity/

14. National Center for Health Statistics. Health, United States, 2015: with special feature on racial and ethnic health disparities. Report No.: 2016-1232. Updated June 22, 2017. Accessed November 11, 2020. https://www.cdc.gov/nchs/data/ hus/hus15.pdf

15. Yancy CW, Wang TY, Ventura HO, et al. The coalition to reduce racial and ethnic disparities in cardiovascular disease outcomes (credo): why credo matters to cardiologists. J Am Coll Cardiol. 2011;57(3):245-52. 
16. Jenkins C, Pope C, Magwood G, et al. Expanding the chronic care framework to improve diabetes management: the REACH case study. Prog Community Health Partnersh. 2010;4(1):65-79.

17. American Cancer Society. Cancer facts \& figures for African Americans 2019-2021. Accessed November 12 2020. https://www.cancer.org/content/dam/cancer-org/research/ cancer-facts-and-statistics/cancerfacts-and-figures-for-african-americans/ cancer-facts-and-figures-for-africanamericans-2019-2021.pdf

18. Dong X, Tsang CCS, Wan JY, et al. Exploring racial and ethnic disparities in medication adherence among Medicare comprehensive medication review recipients. Explor Res Clin Soc Pharm. 2021;3:100041.

19. Cooper D. Workers of color are far more likely to be paid poverty-level wages than white workers. Economic Policy Institute. Working Economics Blog. June 21, 2018. Accessed November 17, 2020. https://www.epi.org/blog/ workers-of-color-are-far-more-likely-tobe-paid-poverty-level-wages-than-whiteworkers /

20. Gould E, Wilson V. Black workers face two of the most lethal preexisting conditions for coronavirus-racism and economic inequality. Economic Policy Institute. June 1, 2020. Accessed November 19, 2020. https://www.epi.org/ publication/black-workers-covid/

21. Joint Economic Committee. The economic state of Black America in 2020. February 14, 2020. Accessed November 17, 2020. https://www. jec.senate.gov/public/ cache/files/ ccf4dbe2-810a-44f8-b3e7-14f7e5143ba6/ economic-state-of-black-america-2020. pdf

22. Brown EJ, Polsky D, Barbu CM, Seymour JW, Grande D. Racial disparities in geographic access to primary care in Philadelphia. Health Aff (Millwood). 2016;35(8):1374-81.

23. Qato DM, Daviglus ML, Wilder J, Lee T, Qato D, Lambert B. 'Pharmacy deserts' are prevalent in Chicago's predominantly minority communities, raising medication access concerns. Health Aff (Millwood). 2014;33(11):1958-65.
24. Kerse N, Buetow S, Mainous AG 3rd, Young G, Coster G, Arroll B. Physicianpatient relationship and medication compliance: a primary care investigation. Ann Fam Med. 2004;2(5):455-61.

25. Walker RJ, Strom Williams J, Egede LE. Influence of race, ethnicity and social determinants of health on diabetes outcomes. Am J Med Sci. 2016;351(4):366-73.

26. McQuaid EL, Landier W. Cultural issues in medication adherence: disparities and directions. J Gen Intern Med. 2018;33(2):200-06.

27. Jaiswal J, Halkitis PN. Towards a more inclusive and dynamic understanding of medical mistrust informed by science. Behav Med. 2019;45(2):79-85.

28. Patel MR, Piette JD, Resnicow K, Kowalski-Dobson T, Heisler M. Social determinants of health, cost-related nonadherence, and cost-reducing behaviors among adults with diabetes: findings from the National Health Interview Survey. Med Care. 2016;54(8):796-803.

29. Patel MR, Kruger DJ, Cupal S, Zimmerman MA. Effect of financial stress and positive financial behaviors on costrelated nonadherence to health regimens among adults in a community-based setting. Prev Chronic Dis. 2016;13:E46.

30. Nekui F, Galbraith AA, Briesacher BA, et al. Cost-related medication nonadherence and its risk factors among Medicare beneficiaries. Med Care. 2021;59(1):13-21.

31. Briesacher BA, Gurwitz JH,

Soumerai SB. Patients at-risk for costrelated medication nonadherence: a review of the literature. J Gen Intern Med. 2007;22(6):864-71.

32. Herman D, Afulani P, Coleman-Jensen A, Harrison GG. Food insecurity and costrelated medication underuse among nonelderly adults in a nationally representative sample. Am J Public Health. 2015;105(10):e48-59.

33. Berkowitz SA, Seligman HK, Choudhry NK. Treat or eat: food insecurity, cost-related medication underuse, and unmet needs. Am J Med. 2014;127(4):303-310.e303.

34. Cohen AJ, Rudolph JL, Thomas KS, et al. Food insecurity among veterans: resources to screen and intervene. Fed Pract. 2020;37(1):16-23.
35. Billimek J, Sorkin DH. Food insecurity, processes of care, and self-reported medication underuse in patients with type 2 diabetes: results from the California Health Interview Survey. Health Serv Res. 2012;47(6):2159-68.

36. Piette JD, Wagner TH, Potter MB, Schillinger D. Health insurance status, cost-related medication underuse, and outcomes among diabetes patients in three systems of care. Med Care. 2004;42(2):102-09.

37. Kushel MB, Gupta R, Gee L, Haas JS Housing instability and food insecurity as barriers to health care among lowincome Americans. J Gen Intern Med. 2006;21(1):71-77.

38. Adams AS, Madden JM, Zhang F, et al. Changes in use of lipid-lowering medications among black and white dual enrollees with diabetes transitioning from Medicaid to Medicare Part D drug coverage. Med Care. 2014;52(8):695-703.

39. Williams LG, Peacock E, Joyce C, et al. Risk factors for low pharmacy refill adherence among older hypertensive men and women by race. Am J Med Sci. 2018;356(5):464-75.

40. Lee M, Salloum RG. Racial and ethnic disparities in cost-related medication non-adherence among cancer survivors. J Cancer Surviv. 2016;10(3):534-44.

41. Attiya A, Reck J. States curb racial inequities in Rx drug affordability with targeted legislation. October 26, 2020. Accessed February 22, 2021. https://www.nashp.org/ states-curb-racial-inequities-in-rx-drugaffordability-with-targeted-legislation/

42. Ho SC, Jacob SA, Tangiisuran B. Barriers and facilitators of adherence to antidepressants among outpatients with major depressive disorder: a qualitative study. PLoS One. 2017;12(6):e0179290.

43. Dossa AR, Moisan J, Guénette L, Lauzier S, Grégoire JP. Association between interpersonal continuity of care and medication adherence in type 2 diabetes: an observational cohort study. CMAJ Open. 2017;5(2):E359-64.

44. Polonsky WH, Henry RR. Poor medication adherence in type 2 diabetes: recognizing the scope of the problem and its key contributors. Patient Prefer Adherence. 2016;10:1299-307. 
45. Oyekan E, Nimalasuriya A, Martin J, Scott R, Dudl RJ, Green K. The B-SMART appropriate medication-use process: a guide for clinicians to help patientsPart 2: adherence, relationships, and triage. Perm J. 2009;13(4):50-54.

46. Pednekar P, Peterson A. Mapping pharmacy deserts and determining accessibility to community pharmacy services for elderly enrolled in a State Pharmaceutical Assistance Program. PLoS One. 2018;13(6):e0198173.

47. Tharumia Jagadeesan C, Wirtz VJ. Geographical accessibility of medicines: a systematic literature review of pharmacy mapping. J Pharm Policy Pract. 2021;14(1):28.

48. Wisseh C, Hildreth K, Marshall J, Tanner A, Bazargan M, Robinson P. Social determinants of pharmacy deserts in Los Angeles county. J Racial Ethn Health Disparities. 2021;8(6):1424-34.

49. Qato DM, Alexander GC, Chakraborty A, Guadamuz JS, Jackson JW. Association between pharmacy closures and adherence to cardiovascular medications among older US adults. JAMA Netw Open. 2019;2(4):e192606.

50. Tello M. Racism and discrimination in health care: Providers and patients. Harvard Health Blog. January 16, 2017. Updated July 9, 2020. Accessed November 11, 2020. https://www.health.harvard. edu/blog/racism-discrimination-healthcare-providers-patients-2017011611015

51. Hardeman RR, Medina EM, Kozhimannil KB. Structural racism and supporting Black lives - the role of health professionals. N Engl J Med. 2016;375(22):2113-15.

52. Sexton SM, Richardson CR, Schrager SB, et al. Systemic racism and health disparities: a statement from editors of family medicine journals. PRiMER. 2020;4:30.

53. Nong P, Raj M, Creary M, Kardia SLR, Platt JE. Patient-reported experiences of discrimination in the US health care system. JAMA Network Open. 2020;3(12):e2029650-e2029650.

54. Centers for Disease Control and Prevention. The Tuskegee timeline. April 22, 2021. Accessed May 23, 2021. https:// www.cdc.gov/tuskegee/timeline.htm

55. Johns Hopkins Medicine. Honoring Henrietta: the legacy of Henrietta Lacks. Accessed March 15, 2021. https://www. hopkinsmedicine.org/henriettalacks/
56. Hostetter M, Klein S. Understanding and ameliorating medical mistrust among Black Americans. The Commonwealth Fund. January 14, 2021. Accessed June 1, 2021. https://www. commonwealthfund.org/publications/ newsletter-article/2021/jan/ medical-mistrust-among-black-americans

57. Nanna MG, Navar AM, Zakroysky P, et al. Association of patient perceptions of cardiovascular risk and beliefs on statin drugs with racial differences in statin use: insights from the patient and provider assessment of lipid management registry. JAMA Cardiol. 2018;3(8):739-48.

58. Dale SK, Bogart LM, Wagner GJ, Galvan FH, Klein DJ. Medical mistrust is related to lower longitudinal medication adherence among African-American males with HIV. J Health Psychol. 2016;21(7):1311-21.

59. Sun K, Eudy AM, CriscioneSchreiber LG, et al. Racial disparities in medication adherence between African American and Caucasian patients with systemic lupus erythematosus and their associated factors. ACR Open Rheumatol. 2020;2(7):430-37.

60. Williams JC. Black Americans don't trust our healthcare system - here's why. The Hill. August 24, 2017. Accessed March 19, 2021. https://thehill.com/ blogs/pundits-blog/healthcare/347780black-americans-dont-have-trust-in-ourhealthcare-system

61. Kalichman SC, Eaton L, Kalichman MO, Grebler T, Merely C, Welles B. Race-based medical mistrust, medication beliefs and HIV treatment adherence: test of a mediation model in people living with HIV/AIDS. J Behav Med. 2016;39(6):1056-64.

62. Pellowski JA, Price DM, Allen AM, Eaton LA, Kalichman SC. The differences between medical trust and mistrust and their respective influences on medication beliefs and ART adherence among African-Americans living with HIV. Psychology \& Health. 2017;32(9):1127-39.

63. Arnett MJ, Thorpe RJ Jr, Gaskin DJ, Bowie JV, LaVeist TA. Race, medical mistrust, and segregation in primary care as usual source of care: Findings from the exploring health disparities in integrated communities study. J Urban Health. 2016;93(3):456-67.
64. Centers for Disease Control and Prevention. What is health literacy? January 28, 2021. Accessed March 19, 2021. https://www.cdc.gov/healthliteracy/ learn/index.html

65. Miller TA. Health literacy and adherence to medical treatment in chronic and acute illness: a meta-analysis. Patient Educ Couns. 2016;99(7):1079-86.

66. Osborn CY, Cavanaugh K, Wallston KA, et al. Health literacy explains racial disparities in diabetes medication adherence. J Health Commun. 2011;16 Suppl 3(Suppl 3): 268-78.

67. Davis SN, Wischhusen JW, Sutton SK, et al. Demographic and psychosocial factors associated with limited health literacy in a community-based sample of older Black Americans. Patient Educ Couns. 2020;103(2):385-91.

68. Adams AS, Banerjee S, Ku CJ. Medication adherence and racial differences in diabetes in the USA: an update. 2015. Diabetes Manag. 2015;5(2):79-87. Accessed January 8, 2021. https://www. openaccessjournals.com/articles/ medication-adherence-and-racialdifferences-in-diabetes-in-the-usaan-update.pdf

69. Schillinger D. The intersections between social determinants of health, health literacy, and health disparities. Stud Health Technol Inform. 2020;269:22-41.

70. Stormacq C, Van den Broucke S, Wosinski J. Does health literacy mediate the relationship between socioeconomic status and health disparities? Integrative review. Health Promot Int. 2019;34(5):e1-17.

71. Kressin NR, Elwy AR, Glickman M, et al. Beyond medication adherence: The role of patients' beliefs and life context in blood pressure control. Ethn Dis. 2019;29(4):567-76.

72. Choudhry NK, Bykov K, Shrank WH, et al. Eliminating medication copayments reduces disparities in cardiovascular care. Health Aff (Millwood). 2014;33(5):863-70.

73. Hussein M, Waters TM, Chang CF, Bailey JE, Brown LM, Solomon DK. Impact of Medicare Part D on racial disparities in adherence to cardiovascular medications among the elderly. Med Care Res Rev. 2016;73(4):410-36. 
74. Rash JA, Campbell DJ, Tonelli M, Campbell TS. A systematic review of interventions to improve adherence to statin medication: What do we know about what works? Prev Med. 2016;90:155-69.

75. Anderson LJ, Nuckols TK, Coles C, et al. A systematic overview of systematic reviews evaluating medication adherence interventions. Am J Health Syst Pharm. 2020;77(2):138-47.

76. Duru OK, Schmittdiel JA, Dyer WT, et al. Mail-order pharmacy use and adherence to diabetes-related medications. Am J Manag Care. 2010;16(1):33-40.

77. Ramachandran B, Trinacty CM, Wharam JF, et al. A randomized encouragement trial to increase mail order pharmacy use and medication adherence in patients with diabetes. J Gen Intern Med. 2021;36(1):154-61.

78. Schwab P, Racsa P, Rascati K, Mourer M, Meah Y, Worley K. A retrospective database study comparing diabetes-related medication adherence and health outcomes for mail-order versus community pharmacy. J Manag Care Spec Pharm. 2019;25(3):332-40. doi:10.18553/jmcp.2019.25.3.332

79. Pittman DG, Tao Z, Chen W, Stettin GD. Antihypertensive medication adherence and subsequent healthcare utilization and costs. Am J Manag Care. 2010;16(8):568-76.

80. Schmittdiel JA, Karter AJ, Dyer W, et al. The comparative effectiveness of mail order pharmacy use vs. local pharmacy use on LDL-C control in new statin users. J Gen Intern Med. 2011;26(12):1396-402.

81. Neil WP, Shiokari CE, Burchette RJ, Stapleton D, Ovbiagele B. Mail order pharmacy use and adherence to secondary prevention drugs among stroke patients. J Neurol Sci. 2018;390:117-20.

82. Doshi JA, Lim R, Li P, et al. A synchronized prescription refill program improved medication adherence. Health Aff (Millwood). 2016;35(8):1504-12.

83. Krumme AA, Glynn RJ, Schneeweiss S, et al. Medication synchronization programs improve adherence to cardiovascular medications and health care use. Health Aff (Millwood). 2018;37(1):125-33.

84. Ma J, Wang L. Characteristics of mailorder pharmacy users: results from the Medical Expenditures Panel Survey. J Pharm Pract. 2020;33(3):293-98.
85. Schmittdiel JA, Marshall CJ, Wiley D, et al. Opportunities to encourage mail order pharmacy delivery service use for diabetes prescriptions: a qualitative study. BMC Health Serv Res. 2019;19(1):422.

86. Conn VS, Enriquez M, Ruppar TM, Chan KC. Cultural relevance in medication adherence interventions with underrepresented adults: systematic review and meta-analysis of outcomes. Prev Med. 2014;69:239-47.

87. Caffrey M. Humana's Bold Goal program takes aim at chronic disease in time of COVID-19. Am J Manag Care blog. June 18, 2020. Accessed September 23, 2021. https://www.ajmc.com/view/ humanas-bold-goal-program-takes-aimat-chronic-disease-in-time-of-covid19

88. Cuffee YL, Hargraves JL, Rosal M, et al. Reported racial discrimination, trust in physicians, and medication adherence among inner-city African Americans with hypertension. Am J Public Health. 2013;103(11):e55-62.

89. Smedley BD, Stith AY, Colburn L, et al; Institute of Medicine. Increasing racial and ethnic diversity among physicians: an intervention to address health disparities? In: The Right Thing To Do, The Smart Thing To Do: Enhancing Diversity in the Health Professions. Summary of the Symposium on Diversity in Health Professions in honor of Herbert W. Nickens, M.D. National Academies Press; 2001. Accessed June 29, 2021. https://www.ncbi.nlm.nih.gov/books/ NBK223632/

90. Street RL, O'Malley KJ, Cooper LA, Haidet P. Understanding concordance in patient-physician relationships: personal and ethnic dimensions of shared identity. Ann Fam Med. 2008;6(3):198-205.

91. Alsan M, Garrick O, Graziani G. Does diversity matter for health? Experimental evidence from Oakland. Am Econ

Rev. 2019;109(12): 4071-111. doi:10.1257/ aer.20181446

92. Ferdinand KC, Yadav K, Nasser SA, et al. Disparities in hypertension and cardiovascular disease in blacks: the critical role of medication adherence. J Clin Hypertens (Greenwich). 2017;19(10):1015-24.

93. Ogedegbe G, Chaplin W, Schoenthaler A, et al. A practice-based trial of motivational interviewing and adherence in hypertensive African Americans. Am J Hypertens. 2008;21(10):1137-43.
94. Izeogu C, Kalinowski J, Schoenthaler A. Strategies to improve adherence to anti-hypertensive medications: a narrative review. Curr Hypertens Rep. 2020;22(12):105.

95. Victor RG, Lynch K, Li N, et al. A cluster-randomized trial of blood-pressure reduction in Black barbershops. N Engl J Med. 2018;378(14):1291-301.

96. Victor RG, Blyler CA, Li N, et al. Sustainability of blood pressure reduction in Black barbershops. Circulation. 2019;139(1):10-19.

97. Gerber BS, Cho YI, Arozullah AM, Lee SY. Racial differences in medication adherence: a cross-sectional study of Medicare enrollees. Am J Geriatr Pharmacother. 2010;8(2):136-45.

98. Pladevall M, Williams LK, Potts LA, Divine G, Xi H, Lafata JE. Clinical outcomes and adherence to medications measured by claims data in patients with diabetes. Diabetes Care. 2004;27(12):2800-05.

99. Shrank WH. Future of value-based care: pharmacy+ primary care integration. Presented at: Pharmaceutical Care Management Association Business Forum. February 19, 2021. Accessed January 27, 2022. https://www.pcmanet.org/events/ past-events/spcma-business-forum-2021/

100. Centers for Medicare \& Medicaid Services. Limited Data Set (LDS) files. Accessed February 2021. https:// www.cms.gov/Research-StatisticsData-and-Systems/Files-for-Order/ LimitedDataSets

101. Centers for Medicare \& Medcaid Services. 2019 star ratings fact sheet. October 13, 2020. Accessed February 2021. https://www.cms.gov/files/document/20 21starratingsfactsheet-10-13-2020.pdf

102. Humana. Humana foundation invests 5.4 Million in eight communities to address social determinants of health. May 5, 2021. Accessed June 1, 2021. https://press.humana. com/news/news-details/2021/ Humana-Foundation-Invests-5.4-Millionin-Eight-Communities-to-AddressSocial-Determinants-of-Health/default. aspx\#gsc.tab $=0$ 